\title{
Prospective and retrospective memory in normal aging and dementia: An experimental study
}

\author{
ELIZABETH A. MAYLOR \\ University of Warwick, Coventry, England \\ and \\ GEOFF SMITH, SERGIO DELLA SALA, and ROBERT H. LOGIE \\ University of Aberdeen, Aberdeen, Scotland
}

\begin{abstract}
Two experiments investigated the effects of normal aging and dementia on laboratory-basedprospective memory (PM) tasks. Participants viewed a film for a later recognition memory task. In Experiment 1, they were also required either to say "animal" when an animal appeared in the film (event-based PM task) or to stop a clock every 3 min (time-based PM task). In both tasks, young participants were more successful than older participants, who were, in turn, more successful than patients with Alzheimer's disease (AD). For successful remembering in the time-based task, older participants and AD patients checked the clock more often than did young participants. In Experiment 2, participants were asked to reset a clock either when an animal appeared in the film (unrelated cue-action) or when a clock appeared in the film (related cue-action). Responses were faster in the related condition than in the unrelated condition. Again, there were differences in PM performance between young and older participants, and between older participants and $\mathrm{AD}$ patients. The observed deficits were not due to the forgetting of the PM task instructions in either experiment. Retrospective memory (RM) tasks (digit span, sentence span, free recall, and recognition) were more impaired by AD than were the PM tasks. Factor analysis revealed separate factors corresponding to RM and PM.
\end{abstract}

Studies of memory in both normal aging and dementia have largely focused on tests of retrospective memory (RM). These usually involve the presentation of information that the participant or patient is subsequently required to recognize or recall in response to some prompt from the experimenter. Thus RM decline has been well documented in both normal aging (e.g., Craik, Anderson, Kerr, \& Li, 1995; Hultsch, Hertzog, Dixon, \& Small, 1998; Zacks, Hasher, \& Li, 2000) and dementia (e.g., Morris, 1996; Nebes, 1992; Spinnler, 1999). In contrast, studies of prospective memory (PM), requiring participants to remember to do something in the future without any prompting such as explicit instructions to recall, have been relatively neglected. However, because of the importance of the successful functioning of PM to living independently in the community (Cockburn \& Smith, 1988; Sinnott, 1989), there has recently been a growing interest in PM (Brandimonte, Einstein, \& McDaniel, 1996). In particu-

This research was funded by The Wellcome Trust (Grant 047065) and the Medical Research Council (Grant G9606610N). We are grateful to Sarah MacPherson for conducting the vigilance experiment and to Fergus Craik, Christopher Hertzog, and an anonymous reviewer for helpful comments on earlier versions of the paper. Correspondence should be addressed to E. A. Maylor, Department of Psychology, University of Warwick, Coventry CV4 7AL, England (e-mail: elizabeth.maylor@ warwick.ac.uk). lar, both naturalistic and laboratory studies have addressed the effects of normal aging on PM, although with somewhat mixed results (see Maylor, 1993b, 1996b; Maylor, Darby, Logie, Della Sala, \& Smith, 2002, for reviews).

A useful framework for considering age deficits across different memory tasks was suggested by Craik (1986). His proposal was that performance is determined by an interaction between external factors such as cues and context (or, more generally, environmental support) and by the type of processing operation required by the task. Craik argued that self-initiated mental activities, such as retrieval, are particularly difficult in old age, but that age-related deficits can be reduced in situations in which environmental support is high. In the resulting hierarchy of memory tasks, PM tasks were placed at the top since, by definition, they are low in environmental support and require a high degree of self-initiated activity; consequently, they should be the most impaired by old age. Below PM tasks in the hierarchy came RM tasks of free recall, cued recall, recognition, and priming, in descending order of age deficits. Thus, the clear prediction from Craik's analysis was that age-related memory impairments should be greater in PM tasks than in RM tasks.

Since Craik's (1986) suggestion, numerous studies have investigated the effects of normal aging on performance in PM tasks conducted both inside and outside the laboratory. In some cases, age deficits in PM performance have 
been observed that are, at least in some respects, more striking than age deficits in RM performance (e.g., Cockburn \& Smith, 1991; Mäntylä \& Nilsson, 1997; Maylor, 1993a, 1996a). However, in other cases, equivalent PM performance in young and older adults has been found in the context of age-related decline in RM performance (e.g., Einstein \& McDaniel, 1990; Maylor, 1990). Age deficits are therefore not always greater in PM tasks than in RM tasks, contrary to Craik's suggestion.

These mixed findings in the literature may be partly explained by the fact that PM tasks themselves vary as much as RM tasks in terms of external factors and processing demands (see Kvavilashvili, 1992). In other words, it is probably not the case that all PM tasks are low in environmental support and high in self-initiated activity. For example, age deficits are often absent in PM tasks conducted outside the laboratory, where participants are able to set up appropriate external cues (see Maylor, 1993b, for a summary), and age deficits in the laboratory are greater when processing demands increase (e.g., Einstein, Holland, McDaniel, \& Guynn, 1992; Einstein, McDaniel, Manzi, Cochran, \& Baker, 2000; Einstein, Smith, McDaniel, \& Shaw, 1997; Kidder, Park, Hertzog, \& Morrell, 1997; Maylor et al., 2002). Craik's (1986) framework therefore remains useful in understanding different effects of normal aging across PM studies.

One way in which PM tasks differ is in terms of whether the trigger for action is a particular event or a particular time (event based vs. time based, respectively; Einstein \& McDaniel, 1990). For example, compare remembering to make a telephone call when you next see a telephone with remembering to make a telephone call at 1600 hours. A number of laboratory studies have found smaller age deficits in event-based PM tasks than in time-based PM tasks (e.g., Einstein, McDaniel, Richardson, Guynn, \& Cunfer, 1995; Park, Hertzog, Kidder, Morrell, \& Mayhorn, 1997; but see also d'Ydewalle, Luwel, \& Brunfaut, 1999). These findings can be readily interpreted within Craik's (1986) framework by supposing that age deficits are less apparent in event-based tasks because the target event itself provides a strong external cue to support performance, and therefore self-initiated retrieval is unnecessary. In time-based tasks, however, environmental support is low and self-initiated retrieval is high because participants have to remember to monitor the time effectively (for evidence that older adults check the clock less often than young adults in time-based PM tasks, see Einstein et al., 1995; Hohaus, Shum, White, \& Caird, 2000; Park et al., 1997).

In contrast to the extensive literature on normal aging and PM, there have been surprisingly few studies of PM in dementia (see Maylor et al., 2002, for discussion of possible reasons for this). Anecdotal evidence suggests that people initially consult their doctors because of their relatives' PM rather than RM problems (e.g., Camp, Foss, Stevens, \& O'Hanlon, 1996; McKitrick, Camp, \& Black, 1992). From a recent questionnaire study by Smith, Della Sala, Logie, and Maylor (2000), it would appear that this is because patients' $\mathrm{PM}$ failures are more frustrating to carers (although no more prevalent) than are their RM failures.

To our knowledge, the only experimental study to attempt a comparison between PM and RM deficits in dementia was by Huppert and Beardsall (1993), although, as noted below, whether their PM task was a true test of PM has been questioned. They focused in particular on a specific item on the Rivermead Behavioral Memory Test (Wilson, Cockburn, \& Baddeley, 1985)—namely, "remembering to deliver a message." The procedure is as follows. The tester asks the participant to "watch what I do, and when I have finished, do the same thing." The tester then traces a short path around the room, describing each action en route: "I am going to start from this chair, and take this envelope with me. From here I am going over to the door. And from the door to the window. From the window to the table. I am going to leave this envelope on the table, and from here I am going back to the chair."

Huppert and Beardsall (1993) scored performance separately for remembering to pick up the envelope at the start and place it down at the end (defined as PM), and remembering each stage of the route in the correct order (defined as RM). They found that for the PM component, those with minimal dementia were similar to those with mild or moderate dementia, whereas for the RM component, those with minimal dementia were more similar to the normal controls. Huppert and Beardsall therefore concluded that PM impairment may be an earlier indicator of dementia than RM impairment. However, other interpretations are possible (see Maylor, 1995, for discussion). For example, it could be argued that the PM component does not correspond with the usual definition of remembering in the future without being prompted because participants were specifically asked by the tester to repeat the sequence of actions just observed. Thus, there seems to be no logical basis for defining certain elements of the sequence as prospective and others as retrospective. Instead the task could be described as a RM test of serial recall for actions. The fact that some elements in the sequence are more likely to be omitted than others in the early stages of dementia could reflect differences in difficulty across the various elements. Clearly, further empirical investigations are required to address Huppert and Beardsall's suggestion that PM tasks are particularly sensitive to the early stages of dementia.

The aim of the present study was to examine the effects of both normal aging and dementia across a range of PM and RM tasks. Young adults, older adults, and patients diagnosed as possibly or probably suffering from Alzheimer's disease $(\mathrm{AD})$ were compared in two experiments. In Experiment 1 , we were concerned with the distinction between event- and time-based PM tasks. Participants were asked to view a short film for a subsequent memory test and also to indicate either whenever an animal appeared in the film (event-based PM task) or whenever 3 min had elapsed (time-based PM task). In the latter case, a clock was positioned out of view (to one side) of the participant 
so that a head movement was required to see the time. Thus, we were able to record clock-checking behavior (see Ceci, Baker, \& Bronfenbrenner, 1988; Ceci \& Bronfenbrenner, 1985; Einstein et al., 1995; Harris \& Wilkins, 1982; Hohaus et al., 2000; Park et al., 1997). Our main prediction with respect to normal aging was that deficits would be less apparent in the event-based PM task than in the time-based PM task because of the greater environmental support provided by the target event occurring in the film relative to the (not directly visible) clock showing that 3 min had elapsed. In general, the RM literature suggests that there are similarities between the effects of normal and abnormal aging (e.g., priming is less impaired by both normal aging and dementia than is free recall; see Prull, Gabrieli, \& Bunge, 2000). We therefore expected a greater deficit due to dementia in the time-based PM task than in the event-based PM task.

The comparison in Experiment 2 was between two event-based PM tasks in which the relationship between the PM cue event and the corresponding action was manipulated. Thus participants reset a clock in response either to the appearance of a clock in the film ("see a clockstop the clock"; related cue-action) or to the appearance of an animal ("see an animal-stop the clock"; unrelated cue-action). The related condition was assumed to be less demanding than the unrelated condition in terms of retrieval processes and environmental support (see Craik, 1986). We therefore predicted that the effects of both normal aging and dementia would be smaller in the related than in the unrelated condition.

In both experiments, we recorded not only whether participants successfully responded to the PM cues for action but also when they responded. As West and Craik (1999) have recently shown for event-based tasks, response times to PM cues can provide sensitive measures of the accessibility or level of activation of the PM task. For time-based tasks, precise response times indicate how accurately participants are able to monitor the time and how well they are able to keep the PM task in mind during an ongoing task. In providing more sensitive assessments of PM performance, response times may be particularly useful in cases where some groups are close to ceiling in terms of the number of correct PM responses.

As argued elsewhere (Maylor, 1995, 1996b; Maylor et al., 2002), in studying PM in normal aging and dementia, it is particularly important to separate PM from RM failures. Thus, in a PM task, participants are required to remember not only that something has to be done (PM component) but also what has to be done, and when and where (RM component). Studies of PM have consequently attempted to keep the RM component as simple as possible to ensure that performance is determined by PM rather than by RM (e.g., Maylor, 1998). However, retaining the PM task requirements may not be such a trivial task for dementia patients. Indeed, Huppert, Johnson, and Nickson (2000) observed that $60 \%$ of a group of individuals with probable dementia (mean age of 81.5 years) failed to show intact $\mathrm{RM}$ for a PM task that required participants to remember that after a task involving an envelope, they were to turn it over, seal it, and write their initials on the back. Thus patients may perform poorly in a PM task, not necessarily because of impaired PM, but because of impaired RM. In the present study, therefore, we questioned participants at the end of testing to ensure that both patients and controls had successfully retained the PM task instructions.

The present PM tasks were designed to provide reasonably naturalistic simulations of everyday PM tasks such as remembering to look out for a post box while shopping (see our event-based task in Experiment 1) or remembering to return to the kitchen after 3 min when boiling an egg (see our time-based task). To anticipate, Experiment 1 was more successful than Experiment 2 in producing significant effects of the various task manipulations in terms of the numbers of correct PM responses. Nevertheless, the two experiments together provided the opportunity to combine the data to produce sufficiently large numbers of participants to test Huppert and Beardsall's (1993) proposal that PM is more prone to decline than RM in the early stages of dementia. Thus we included a number of RM tasks in both experiments for comparison-namely, digit span, sentence span, free recall, and recognition. At least some of these RM tasks were approximately comparable with the PM tasks in terms of retention interval. From Craik's (1986) framework, they were expected to produce a range of aging and dementia deficits, with free recall as the most impaired. Note that since PM tasks also differ in many ways (see Kvavilashvili, 1992), our aim was not to compare PM and RM in general (as if they were single entities); rather, we were interested in whether at least some PM tasks are less prone to decline in dementia than at least some RM tasks.

Finally, the issue of the relationship between PM and RM has been much debated in the literature (e.g., see Brandimonte et al., 1996). In addition to addressing this issue by examining whether or not either normal aging or dementia have differential effects on PM and RM, the present study also provided the opportunity to explore the PM-RM relationship through factor analysis on measures from several different memory tests in the search for distinct PM and RM factors.

\section{EXPERIMENT 1}

\section{Method}

Participants. There were three groups of participants: young adults, older adults, and patients with $\mathrm{AD}$. The young participants $(n=30)$ were aged between 19 and 40 years and were undergraduate students at the University of Aberdeen. The older participants $(n=30)$ were aged between 58 and 75 years and were members of a volunteer panel at the Department of Psychology, University of Aberdeen. Both the young and older participants were paid for taking part in the study. AD patients were recruited through the Memory Clinic of the Mental Health Department at the University of Aberdeen. Patients were not included in the present study if they scored below 16 on the Mini-Mental State Examination (MMSE; Folstein, Folstein, \& McHugh, 1975). The patients were diagnosed as suffering from progressive cognitive deterioration due to possible or probable $\mathrm{AD}$ on the basis of formal criteria (Spinnler \& Della Sala, 
1988), which broadly correspond to those proposed by NINCDSADRDA (McKhann et al., 1984). All the patients fulfilled the criteria for inclusion in research studies as set forth by the Medical Research Council's Alzheimer Disease Workshop Steering Committee (Wilcock et al., 1989). Two patients were excluded because they were unable to understand the task instructions. The remaining patients $(n=24)$ were aged between 53 and 84 years and had been attending the Memory Clinic for between 7 and 66 months $(M=30.2$, $S D=18.6$ ). Their MMSE scores ranged from 16 to 27 with a mean of $22.1(S D=3.6)$.

Background details for the three groups of participants are provided in Table 1 . There was no significant age difference between the older adults and the AD patients $[t(52)=-0.75, p>.10]$. An analysis of variance (ANOVA) on years of education revealed a significant effect of group $\left[F(2,81)=9.98, M S_{\mathrm{e}}=9.19, p<.001\right]$. Post hoc Newman-Keuls comparisons showed a marginally significant difference between the young and older participants $(p=.06)$, but a significant difference between the older participants and the AD patients $(p<.01)$.

Three measures of RM are also included in Table 1. Forward digit span was assessed by presenting lists of digits verbally at a rate of one digit per second. Participants were required to recall aloud each list in the correct order. After three trials with two digits, the number of digits increased to three, and so on up to a possible maximum of nine digits. Testing was terminated when there were errors on two of the three trials with a particular list length. Span was calculated by averaging the lengths of the longest three lists accurately recalled. For sentence span, the experimenter read aloud sets of sentences of 4-6 words and then asked participants to recall the last word of each sentence in the correct order. After three trials with one sentence, the number of sentences increased to two, and so on up to a possible maximum of six sentences. Testing was terminated when there were errors on two of the three trials with a particular number of sentences. Span was calculated by averaging the lengths of the longest three sets accurately recalled. Immediate free recall was based on a procedure by Capitani, Della Sala, Logie, and Spinnler (1992). The experimenter read out five lists of 12 unrelated words at a rate of one word per second. Immediately after each list presentation, participants were required to recall aloud the words in any order. The total number of words recalled out of 60 was recorded.

ANOVAs were conducted to compare the RM measures across the three groups of participants. For digit span, there was a significant effect of group $\left[F(2,81)=13.15, M S_{\mathrm{e}}=1.71, p<.001\right]$. There was also a significant effect of group for sentence span $[F(2,81)=$ $\left.34.32, M S_{\mathrm{e}}=0.61, p<.001\right]$. For both digit span and sentence span, post hoc Newman-Keuls comparisons revealed significant differences between the young adults and the AD patients, and between the older adults and the AD patients, but not between the young and older adults. Finally, there was a significant effect of group for free recall $\left[F(2,81)=46.57, M S_{\mathrm{e}}=35.87, p<.001\right]$. In this case, post hoc Newman-Keuls comparisons revealed significant differences between all three groups.

Table 1

Background Data for Participants in Experiment 1

\begin{tabular}{|c|c|c|c|c|c|c|}
\hline \multirow[b]{2}{*}{ Measure } & \multicolumn{2}{|c|}{ Young* } & \multicolumn{2}{|c|}{ Older } & \multicolumn{2}{|c|}{ AD Patientsł } \\
\hline & $M$ & $S D$ & $M$ & $S D$ & $M$ & $S D$ \\
\hline Age (years) & 5.40 & 4.96 & 7.27 & 24 & 8.54 & 8.01 \\
\hline Educatior & 13.83 & & 12 & & & 2.05 \\
\hline Digit span & 6.82 & 1.22 & 7.08 & 1.37 & 5.35 & 1.34 \\
\hline Sentence span & 4.54 & 0.79 & 4.39 & 0.56 & 2.92 & 0.97 \\
\hline Free recall & 35.07 & 7.53 & 25.93 & 4.03 & 19.46 & 5.86 \\
\hline
\end{tabular}

Note-F, females; M, males; AD, Alzheimer's disease. $*_{n} n=30,9 \mathrm{~F}$,

$21 \mathrm{M} . \quad \hbar n=30,18 \mathrm{~F}, 12 \mathrm{M} . \quad \hbar^{\circ}=24,14 \mathrm{~F}, 10 \mathrm{M}$.
Apparatus and Stimuli. A 17-min silent color film of scenes and landmarks in and around the city of Aberdeen was recorded using a hand-held camcorder. During the film, five different animals (a cow, a horse, a dog, a pig, and a sheep) appeared after approximately 3, 6, 9, 12, and $15 \mathrm{~min}$, respectively. Each animal was on the screen for exactly $3 \mathrm{sec}$. The film was prepared so that the animal scenes blended smoothly with the preceding and subsequent scenes. The film was recorded onto a videotape and played back on a color television with a screen diagonal of $711 \mathrm{~mm}$. Still color photographs of 12 scenes from the film and 12 scenes of other Aberdeen locations not included in the film were produced for a 24-item twochoice visual recognition test. Responses in the event-based PM task were timed using a handheld stopwatch.

For the time-based PM task, an analogue clock display was produced on a black-and-white computer screen using Visual Basic. The diameter of the clock was $145 \mathrm{~mm}$. There were lines of $7 \mathrm{~mm}$ extending inward from the perimeter of the clock at $0^{\circ}, 90^{\circ}, 180^{\circ}$, and $270^{\circ}$, and these were labeled $0,1,2$, and 3, respectively. Each of the numbers was $10 \mathrm{~mm}$ high. There were second (length $=145 \mathrm{~mm}$ ) and minute (length $=60 \mathrm{~mm}$ ) hands on the clock. The second hand rotated $360^{\circ}$ per minute whereas the minute hand rotated $90^{\circ}$ per minute. Pressing the space bar on the computer keyboard reset both hands of the clock to zero. The time when the space bar was pressed was recorded by the computer program. The computer screen and keyboard were placed so that the left-hand edge of the screen was at $90^{\circ}$ to the right of participants. This ensured that the clock itself was outside of participants' peripheral vision as they viewed the film, so they would have to turn around to look at the clock. A stopwatch was used by the experimenter to record when participants monitored the clock.

Design and Procedure. Participants were tested individually either in the Department of Psychology or in the Mental Health Department, University of Aberdeen. Half of the participants in each of the three groups were assigned to the event-based PM condition, and half were assigned to the time-based PM condition. In all three groups, the participants assigned to the event-based condition were extremely well matched with the participants assigned to the timebased condition in terms of the background variables shown in Table 1, with just one exception: The AD patients assigned to the event-based condition achieved lower scores for free recall than did those assigned to the time-based condition. AD patients assigned to the event- and time-based conditions had similar MMSE scores and had been attending the Memory Clinic for similar lengths of time.

1. In the event-based condition, AD patients were first shown six pictures. Three of these showed animals that did not appear in the film, and three showed items of furniture. The patients were asked to say whether each picture showed an animal or not; this preliminary test was to ensure that any errors in responding to animals in the PM task were not due to problems other than memory deficits, such as severe visual agnosia. All the patients successfully distinguished between the pictures of animals and furniture.

Participants were told that they were going to view a film. They were encouraged to watch it carefully because they would be asked questions later about its content. They were also instructed to look out for animals in the film and respond by saying "animal" as quickly as possible after seeing one. It was stressed that they should not respond to people or birds. When participants had demonstrated full understanding of the instructions, the experimenter started the film. The delay between the appearance of each animal and the participant's verbal response was recorded by the experimenter, who was seated out of the participant's view.

2. In the time-based condition, the experimenter began by starting the computerized clock and explaining how it displayed the passage of time. Participants were instructed that they would be required to stop and reset the clock by pressing the space bar on the computer keyboard whenever 3 min had elapsed. The experimenter himself pressed the space bar after 3 min to demonstrate how the clock was 


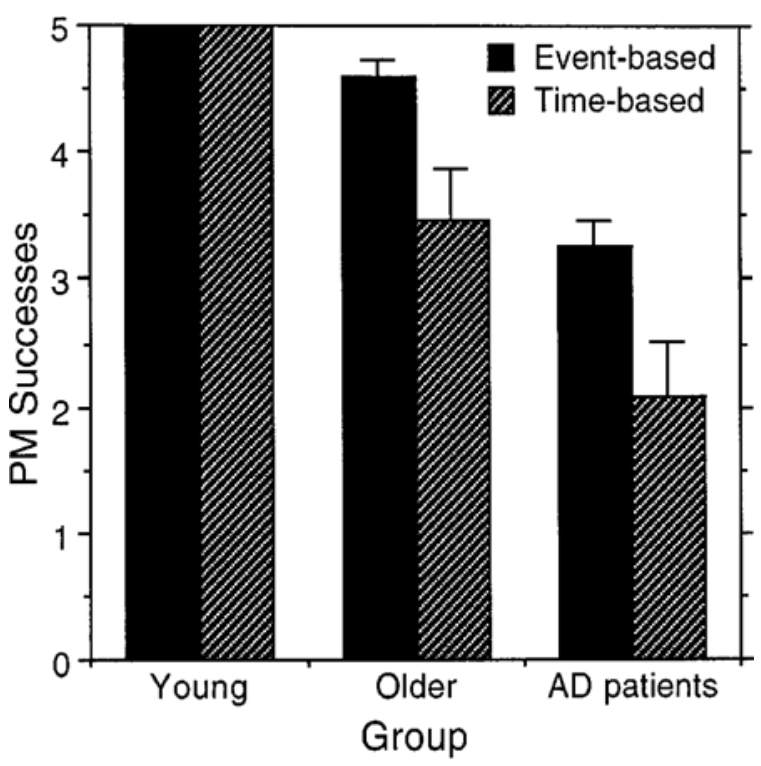

Figure 1. Mean numbers of PM successes out of five in the eventbased and time-based conditions for young adults, older adults, and $A D$ patients in Experiment 1. Error bars represent $1 S E$.

then automatically reset to zero. Participants were instructed to be as accurate as possible and that an early response was as erroneous as a late response. ${ }^{1}$ They were told that they could check the clock as often as they wished. The number and timings of the participants' clock checks were noted by the experimenter.

As in the event-based condition, participants were told that they were going to view a film that they should watch carefully because they would be asked questions later about its content. Participants were then reminded of all the task instructions. When they had demonstrated that they understood all the instructions, the experimenter started the film and the clock simultaneously by pressing a single button connected to the video player and the computer.

At the end of the film in both the event- and time-based conditions, participants were asked to recall what they had been instructed to do while watching the film. If they did not spontaneously recall the PM task instructions, they were prompted to think whether there was anything else they had to do. If they failed to recall the PM task instructions with this prompt, they were reminded of what they were supposed to do and were asked if they recognized the instructions.

Participants in both conditions were then shown 24 photographs one at a time. They were told that some of the scenes appeared in the film whereas others did not. Their task was to respond "yes" or "no" to each photograph depending on whether or not they recognized the scene as having appeared in the film.

Finally, the digit span, sentence span, and free recall tests were administered to all participants (Table 1).

\section{Results}

Recall of PM instructions. When asked at the end of the experiment to recall what they had been instructed to do while watching the film, all participants spontaneously recalled the PM instructions correctly with the exception of $3 \mathrm{AD}$ patients who required only a minimal prompt.

PM scoring. In the event-based condition, a successful PM response was recorded if the participant called out "animal" within $4 \mathrm{sec}$ of the appearance of an animal in the film (which was on screen for $3 \mathrm{sec}$ ). (In fact, there were no responses longer than $4 \mathrm{sec}$.) The delay between the onset of the animal's appearance and the participant's response was recorded to the nearest second..$^{2}$ In the timebased condition, a successful PM response was recorded if the participant stopped the clock between $2 \mathrm{sec}$ before and $2 \mathrm{sec}$ after the clock had reached 3 min. ${ }^{3}$ The absolute time difference between the participant's response and the target time was recorded to the nearest second.

PM performance. Figure 1 displays the mean numbers of PM successes out of five in the event- and timebased conditions for young adults, older adults, and AD patients. ${ }^{4}$ It can be seen that the young adults performed at ceiling in both conditions. Performance for the two older groups was higher for the event-based task than for the time-based task. The young group performed better than the older group and the older group performed better than the AD patients, with the difference between the two older groups being similar for the event-based and time-based tasks.

Because the young participants performed perfectly in both conditions, they were not included in a two-way factorial ANOVA on these data with group (2 levels: older and AD patients) and task (2 levels: event-based and timebased) as factors. There were significant effects of both group $\left[F(1,50)=18.72, M S_{\mathrm{e}}=1.33, p<.001\right]$ and task $\left[F(1,50)=13.26, M S_{\mathrm{e}}=1.33, p<.001\right]$, but there was no significant interaction between them $(F<1)$.

The upper portion of Table 2 shows the mean latencies for successful PM responses in the event-based condition and the mean absolute distances away from the target times for successful PM responses in the time-based condition (i.e., those that fell within the \pm 2 -sec time window). Because these response times are not strictly comparable across the two conditions (e.g., possible response times for the event- and time-based conditions were 0-4 sec and 0-2 sec, respectively), separate ANOVAs were conducted on these data. For the event-based condition, there was a significant effect of group $[F(2,39)=$ $\left.47.80, M S_{\mathrm{e}}=0.23, p<.001\right]$. Newman-Keuls comparisons revealed that the young adults were significantly faster than the older adults $(p<.001)$, and the older adults were marginally faster than the $\operatorname{AD}$ patients $(p=.08)$. For the time-based condition, the effect of group was also significant $\left[F(2,36)=24.14, M S_{\mathrm{e}}=0.22, p<.001\right]$. On

Table 2

Response Time Data and Recognition Memory Performance in Experiment 1

\begin{tabular}{|c|c|c|c|c|c|c|}
\hline \multirow[b]{2}{*}{ Measure } & \multicolumn{2}{|c|}{ Young } & \multicolumn{2}{|c|}{ Older } & \multicolumn{2}{|c|}{ AD Patients } \\
\hline & $M$ & $S D$ & $M$ & $S D$ & $M$ & $S D$ \\
\hline \multicolumn{7}{|c|}{ Response times (sec) } \\
\hline Event based & 0.2 & 0.3 & 1.5 & 0.3 & 1.8 & 0.8 \\
\hline Time based* & 0.3 & 0.4 & 0.5 & 0.5 & 1.6 & 0.6 \\
\hline \multicolumn{7}{|c|}{ Recognition memory (\% correct) } \\
\hline Event based & 93.04 & 8.71 & 90.28 & 8.72 & 68.06 & 5.98 \\
\hline Time based & 92.21 & 9.42 & 91.96 & 6.21 & 71.54 & 9.37 \\
\hline
\end{tabular}

Note—AD, Alzheimer's disease. *One older adult and 2 AD patients missing because of zero PM successes. 
Newman-Keuls comparisons, the young adults were not significantly closer to the target times than the older adults $(p>.10)$, but the older adults were significantly closer than the AD patients $(p<.001)$.

Analysis of the distances away from the target times (i.e., accuracy) for all PM responses in the time-based condition (i.e., regardless of whether or not they fell successfully within the \pm 2 -sec time window) showed that AD patients $(M=10.0 \mathrm{sec}, S D=16.5 \mathrm{sec})$ were less accurate than older adults $(M=6.6 \mathrm{sec}, S D=16.6 \mathrm{sec})$, who were, in turn, less accurate than young adults $(M=$ $0.3 \mathrm{sec}, S D=0.4 \mathrm{sec}$ ). Note also that AD patients made significantly fewer responses (whether accurate or inaccurate) in the time-based condition than did the older adults $(M$ for $\mathrm{AD}$ patients $=4.0 / 5 ; M$ for older adults $=$ $4.8 / 5)[t(25)=-3.20, p<.005]$. Thus, in both event- and time-based conditions, the AD patients missed more $\mathrm{PM}$ targets entirely than the older group and also tended to be slower (event-based) and less accurate (time-based) when they did respond. In comparison with the young adults, the older adults missed more targets and were slower when they did respond in the event-based task, but they produced almost as many responses in the time-based task, albeit with much less accuracy.

Clock-checking behavior. For the time-based condition, we calculated the number of times participants checked the clock in each of the six 30 -sec periods over each 3-min interval leading up to a PM target time. In contrast to previous studies (Einstein et al., 1995; Hohaus et al., 2000; Park et al., 1997), we looked separately at clock-checking behavior leading up to successful PM re- sponses and clock-checking behavior leading up to PM failures. In the former case, 1 older adult and $2 \mathrm{AD}$ patients had to be omitted from the analysis because they never succeeded; in the latter case, all 15 young adults, 5 older adults, and $1 \mathrm{AD}$ patient had to be omitted because they never failed. We initially analyzed the data separately for each of the five 3-min intervals. There were no obvious trends over the course of the experiment, so the data for each participant were averaged across the available trials (maximum of five).

Figure 2 shows the mean numbers of clock checks in the six 30-sec periods leading up to PM success for each group of participants. Clearly, clock checking was most frequent (and very similar across the three groups) in the final period of the 3-min time interval culminating in a PM response. Clock checking in the preceding five periods was much less frequent, particularly for young adults. An ANOVA was conducted on these data with group (3 levels) and period (6 levels) as between- and within-subjects factors, respectively. There were significant effects of group $\left[F(2,36)=8.27, M S_{\mathrm{e}}=0.87, p<.001\right]$ and period $\left[F(5,180)=217.05, M S_{\mathrm{e}}=0.27, p<.001\right]$, but there was no interaction between them $\left[F(10,180)=1.19, M S_{\mathrm{e}}=\right.$ $0.27, p>.10]$. Post hoc Newman-Keuls comparisons indicated that young adults checked the clock significantly less often than both older adults $(p<.05)$ and AD patients $(p<.001)$, and that older adults checked the clock marginally less often than AD patients $(p<.08)$.

In contrast to the J-shaped functions of Figure 2, clock checking in the periods leading up to PM failure remained flat for both older adults and AD patients, with the mean

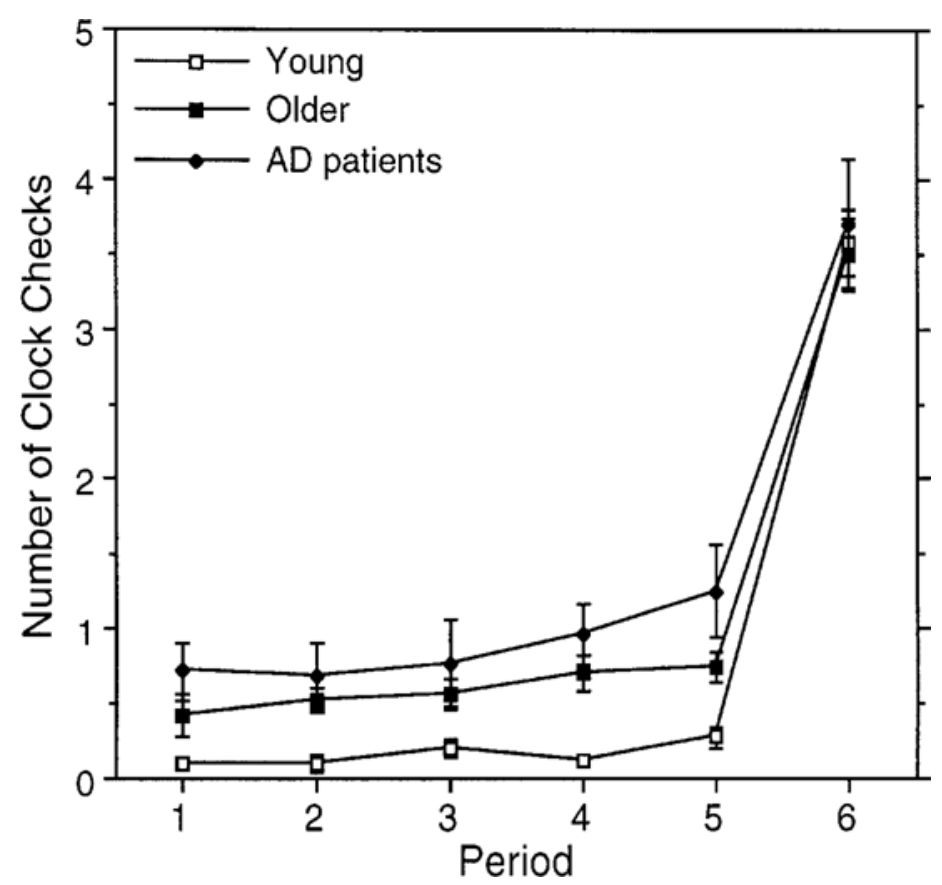

Figure 2. Mean numbers of clock checks leading up to a successful PM response in each 30-sec period of the 3-min intervals in the time-based condition of Experiment 1. Error bars represent $\pm 1 S E$. 
number of clock checks in each period never exceeding 1 . These data were analyzed with group ( 2 levels) and period (6 levels) as between- and within-subjects factors, respectively. There was a significant effect of group $[F(1,19)=$ $\left.5.63, M S_{\mathrm{e}}=0.79, p<.05\right]$, indicating that older adults $(M=0.91)$ checked the clock more often than AD patients $(M=0.54)$. Note that this is the opposite result to the trend observed for periods leading up to PM success, where $\mathrm{AD}$ patients checked the clock more often than older adults (Figure 2). The effect of period was not significant $\left[F(5,95)=1.05, M S_{\mathrm{e}}=0.30, p>.10\right]$, and there was no interaction between group and period $(F<1)$. Although older adults actually checked the clock slightly more often in Periods 1-5 prior to a PM failure than prior to a PM success, it should be remembered that different subsets of older adults were included in the two analyses.

Recognition memory performance. The lower portion of Table 2 summarizes performance in the recognition memory task after film viewing. It can be seen that the mean percentages of correct recognition responses (i.e., "yes" to old scenes from the film and "no" to new scenes) were higher for the young and older adults than for the $\mathrm{AD}$ patients. (Both omissions and false positives were numerically greater for the $\mathrm{AD}$ patients than for the other groups.) The percentages of correct responses were analyzed with group (3 levels) and PM task (2 levels) as between-subjects factors. There was a significant effect of group $\left[F(2,78)=62.10, M S_{\mathrm{e}}=67.53, p<.001\right]$, but no effect of PM task and no interaction (both $F_{\mathrm{S}}<1$ ). Post hoc Newman-Keuls comparisons revealed that the AD patients differed from both the young and older adults (who did not differ).

\section{Discussion}

The first point to emphasize from the results of Experiment 1 is that deficits due to both normal aging and dementia were observed in PM performance, despite having ensured that all participants had successfully retained the PM task instructions. In other words, everyone knew and understood what they were required to do, but older adults, and particularly $\mathrm{AD}$ patients, simply failed to carry out the PM task at the appropriate time. We are therefore dealing here purely with failures of the PM component (see Maylor, 1998).

Second, performance in both event- and time-based PM tasks was impaired by normal aging in such a way that older adults made fewer successful responses than young adults, and were slower (event based) or less accurate (time based) in executing responses generally. The agerelated deficit shown in Figure 1 appeared greater for the time-based task than for the event-based task, consistent with the majority of previous studies, but here, such a comparison is obviously difficult to interpret because of the presence of ceiling effects for young adults. However, in another study using identical tasks (Logie, Maylor, Della Sala, \& Smith, 2001), PM performance was taken down from ceiling by requiring participants to perform an additional arithmetic verification task. PM success was greater for young than for older adults, but there was no sign of an interaction between age and type of PM task. Thus it appears that our particular event- and time-based tasks do not produce differential age deficits.

In contrast to decline in PM performance with normal aging, there was no age-related deficit in performance on the ongoing task of remembering the film for a later recognition task. Note that age deficits in PM tasks have now been observed in the context of similar, superior, and inferior performance on the ongoing task by older adults in comparison with young adults (e.g., Maylor et al., 2002).

Third, event- and time-based PM performances in terms of numbers of successful responses were equally impaired in $\mathrm{AD}$ patients in comparison with age-matched controls (Figure 1). AD patients also tended to be slower (event based) and were less accurate (time based) than older adults. Our prediction was that the time-based PM task would be more impaired by AD than the event-based PM task because (1) time-based tasks are more adversely affected by normal aging than event-based tasks due to their greater reliance on self-initiated retrieval processes, and (2) memory tasks that are particularly impaired by normal aging are often also particularly impaired by dementia. Logie et al.'s (2001) results would suggest that at least the first of these two assumptions does not always hold true (see also d'Ydewalle et al., 1999, for evidence of larger age deficits in event- than in time-based tasks). It seems more plausible that both event- and time-based PM tasks can vary (e.g., in terms of the degree of self-initiated activity required or environmental support available) in such a way that some event-based tasks could be more demanding than some time-based tasks. In other words, a simple distinction between event- and time-based PM tasks in terms of different cues for action (a particular event or time, respectively) may be less useful than originally supposed in predicting both aging and dementia deficits (see also Rabbitt, 1996). Nevertheless, it is of interest that the present event- and time-based PM tasks are similarly impaired by both normal aging (see Logie et al., 2001) and dementia (present data).

Finally, there was greater clock checking in the final 30 -sec period leading up to a target time than in the previous five periods in the time-based PM task (Figure 2), as others have observed (e.g., Einstein et al., 1995; Park et al., 1997). However, if clock-checking behavior prior to PM success and failure is considered separately, the finalperiod increase was evident only prior to PM success. This finding is important because it helps to explain why previous studies of aging (which have not distinguished between clock checking prior to PM success and failure) have found that older adults check the clock less often than young adults, particularly in the final period before the target time (Einstein et al., 1995; Hohaus et al., 2000; Park et al., 1997). Since older adults are more likely than young adults to forget the PM task, exactly this pattern would be expected. In contrast, the present results showed no effects of aging or dementia on clock-checking behavior in the final 30-sec period leading up to PM success, but there were significant differences between groups in clockchecking in the earlier periods such that $\mathrm{AD}$ patients and 
Table 3

Background Data for Participants in Experiment 2

\begin{tabular}{|c|c|c|c|c|c|c|}
\hline \multirow[b]{2}{*}{ Measure } & \multicolumn{2}{|c|}{ Young* } & \multicolumn{2}{|c|}{ Older † } & \multicolumn{2}{|c|}{ AD Patients } \\
\hline & $M$ & $S D$ & $M$ & $S D$ & $M$ & $S D$ \\
\hline Age (years) & 21.15 & & 8 & 98 & 3.72 & 5.85 \\
\hline Education (yea & 15.05 & 1 & 11.95 & 3.12 & 10.56 & 2.85 \\
\hline Digit span & 7.08 & 1.19 & 6.75 & 0.96 & 5.30 & 0.79 \\
\hline Sentence span & 4.62 & 0.99 & 4.23 & 0.95 & 2.83 & 1.16 \\
\hline Free recall & 31.30 & 6.51 & 26.80 & 5.37 & 19.17 & 3.67 \\
\hline
\end{tabular}

Note-F, females; M, males; AD, Alzheimer's disease. $\quad * n=20,11 \mathrm{~F}$,

$9 \mathrm{M} . \quad \hbar n=20,14 \mathrm{~F}, 6 \mathrm{M}$. $\vdots n=18,13 \mathrm{~F}, 5 \mathrm{M}$.

older adults actually checked more often than young adults (Figure 2).

This finding resembles two previous results in the literature. First, Park et al. (1997) observed that young adults checked the clock more frequently under dual-task conditions than under single-task conditions. The more frequent clock checking found in our older participants is therefore consistent with the view that one impact of normal aging is a reduction in processing resources (see Salthouse, 1991, for a summary, but see Baddeley, Logie, Bressi, Della Sala, \& Spinnler, 1986, and Duff \& Logie, 2001, for caveats). Second, Maylor (1998) asked participants at the end of an event-based PM experiment to rate how often they had thought about the PM component during the task. Regression analysis relating these self-rated thoughts to PM performance revealed that for the same level of PM performance, older participants reported thinking about the PM task more than young participants. In other words, for both event-based (Maylor, 1998) and time-based (present study) tasks, successful PM performance was preceded by different behaviors in young and older adults. Thus PM success in old age seems to be achieved by greater effort during the task, either in terms of more thoughts about the task (event based) or more checks on the clock (time based). ${ }^{5}$

It is interesting to note that prior to a PM failure, older adults and $\mathrm{AD}$ patients checked the clock once on average during the final 30 -sec period. This observation is consistent with the view that age-related deficits in PM are not due to the complete forgetting of the PM task demands but instead reflect temporary or momentary lapses of intention (see Craik \& Kerr, 1996; Maylor, 1993a, 1996a; West \& Craik, 1999).

Comparisons between the effects of aging and dementia on RM versus PM, and factor analysis, are postponed until after the presentation of Experiment 2, in which we examined performance on two event-based PM tasks differing in terms of the relationship between the PM cue event and the action required in response to the cue.

\section{EXPERIMENT 2}

\section{Method}

Participants. Three new groups of participants (young adults, older adults, and AD patients) were recruited from the same sources as described for Experiment 1 . The young participants $(n=20)$ were aged between 18 and 29 years and the older participants $(n=20)$ were aged between 55 and 80 years. Both of these groups were paid for their participation in the study. AD patients who were able to understand the task instructions $(n=18)$ fulfilled the same selection criteria as given for Experiment 1. They were aged between 57 and 81 years and had been attending the Memory Clinic for between 8 and 65 months $(M=33.2, S D=18.1)$. Their MMSE scores ranged from 17 to $30(M=20.9, S D=3.8)$.

Table 3 summarizes background information on the three groups of participants. The older adults and AD patients did not differ significantly in age $[t(36)=-0.29, p>.10]$. There was a significant effect of group in an ANOVA on years of education $[F(2,55)=14.58$, $\left.M S_{\mathrm{e}}=6.99, p<.001\right]$, with significant differences on NewmanKeuls comparisons between the young and older adults $(p<.001)$ but not between the older adults and the AD patients $(p>.10)$.

For the RM measures shown in Table 3, there were significant overall effects of group in ANOVAs for digit span $[F(2,55)=16.76$, $\left.M S_{\mathrm{e}}=1.01, p<.001\right]$, for sentence $\operatorname{span}\left[F(2,55)=15.44, M S_{\mathrm{e}}=\right.$ $1.07, p<.001]$, and for free recall $\left[F(2,55)=24.60, M S_{\mathrm{e}}=28.76\right.$, $p<.001]$. As in Experiment 1, Newman-Keuls comparisons revealed significant differences between all three groups with the exception of young versus older adults for digit span and sentence span.

Apparatus and Stimuli. Two 17-min silent color films were used in this experiment. One was the film used in Experiment 1, in which five different animals appeared at approximately 3-min intervals, each for $3 \mathrm{sec}$ (the "animal film"). The other was very similar to the original film in style and content, the main difference being that five different clocks appeared after approximately 3, 6, 9, 12, and $15 \mathrm{~min}$. Each clock was on the screen for exactly $3 \mathrm{sec}$. As before, the clock scenes blended smoothly with the preceding and subsequent scenes. Because this second film differed slightly from the first, a second set of 24 color photographs ( 12 scenes from the film and 12 new scenes) was prepared for the two-choice visual recognition test following the viewing of the "clock film."

The analogue clock display used in Experiment 1 was also used in Experiment 2. The film and the computer clock were synchronized so that PM response times were recorded automatically by the computer. As before, the computer screen and keyboard were placed to the right of the participant so that the clock could not be seen during film viewing.

Design and Procedure. Participants were tested individually either in the Department of Psychology or in the Mental Health Department, University of Aberdeen. Half of the participants in each of the three groups were assigned to the related cue-action condition, and half were assigned to the unrelated cue-action condition. In all three groups, the participants assigned to the related condition were extremely well matched with the participants assigned to the unrelated condition in terms of the background variables shown in Table 3, with just one exception: Participants assigned to the related condition achieved slightly lower scores on the digit span task than those assigned to the unrelated condition, but this was equally the case for all three groups. AD patients assigned to the two conditions had similar MMSE scores and had been attending the Memory Clinic for similar lengths of time.

As in Experiment 1, the experimenter began by checking that all the AD patients in the unrelated cue-action condition were able to recognize animals (see Experiment 1 for procedure). All could distinguish perfectly between pictures of animals and pictures of furniture.

Participants were instructed that they were going to view a film and that they should watch it carefully because they would be asked questions later about its content. They were also instructed to look out for clocks (related cue-action condition) or animals (unrelated cue-action condition). Participants in the related condition were shown the clock film, whereas participants in the unrelated condition were shown the animal film. In response to the appearance of a specified target event, all participants were instructed to stop the clock by pressing the space bar of the computer keyboard as soon as 
possible to reset the hands of the clock to zero. (Note that target events did not occur at exactly 3-min intervals, so there was no suggestion that the time on the clock was informative as to when the next target would appear.) Participants in the unrelated cue-action condition were additionally warned not to respond to people or birds. The delay between the appearance of each target event and the pressing of the space bar was recorded by the computer. When participants had demonstrated that they understood all the task instructions, the experimenter started the film and clock simultaneously by pressing a single button connected to the video player and the computer.

In both conditions, participants were asked at the end of the film to recall what they had been instructed to do while watching the film (see Experiment 1 for details). The two-choice recognition test was then completed, followed by the digit span, sentence span, and free recall tests.

\section{Results}

Recall of PM instructions. When asked at the end of experiment to recall what they had been instructed to do while watching the film, all participants spontaneously recalled the PM task instructions correctly with the following exceptions. In the related condition, $4 \mathrm{AD}$ patients required a minimal prompt. In the unrelated condition, 2 older adults and $4 \mathrm{AD}$ patients required a minimal prompt, and $1 \mathrm{AD}$ patient required more specific prompting. It should be noted that all of these participants who failed to spontaneously recall the PM task instructions carried out the PM task successfully on at least one occasion.

PM scoring. In both conditions, a successful PM response was recorded if the participant pressed the space bar of the computer (which reset the clock) within 6 sec of the appearance of a clock (related condition) or an animal (unrelated condition) in the film (each appearing on screen for $3 \mathrm{sec}$ ). We allowed $2 \mathrm{sec}$ longer than in Exper-

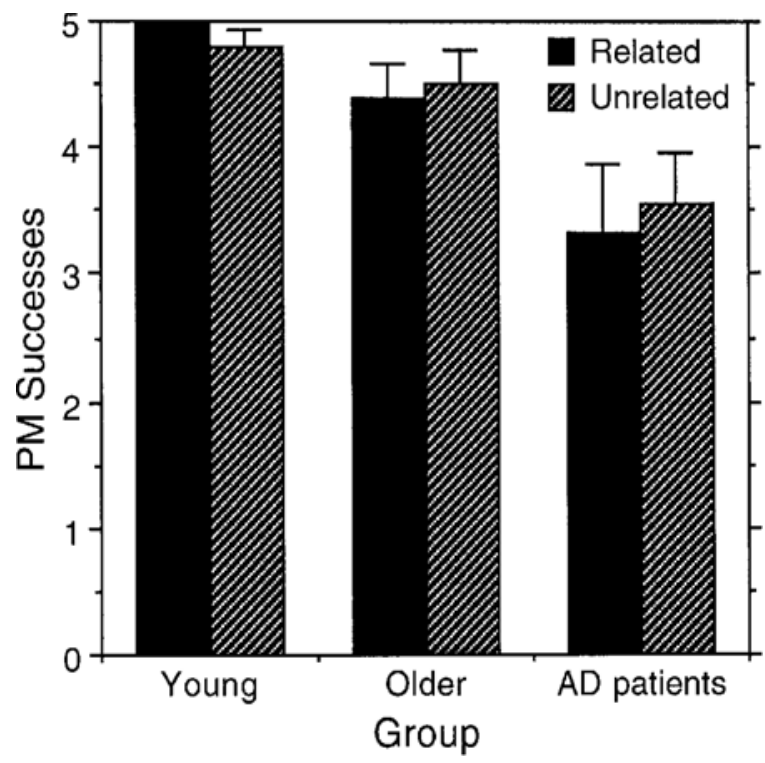

Figure 3. Mean numbers of PM successes out of five in the related cue-action (clock-clock) and unrelated cue-action (animal-clock) conditions for young adults, older adults, and AD patients in Experiment 2. Error bars represent $1 S E$.
Table 4

Response Time Data and Recognition Memory Performance in Experiment 2

\begin{tabular}{|c|c|c|c|c|c|c|}
\hline \multirow[b]{2}{*}{ Measure } & \multicolumn{2}{|c|}{ Young } & \multicolumn{2}{|c|}{ Older } & \multicolumn{2}{|c|}{ AD Patients } \\
\hline & $M$ & $S D$ & $M$ & $S D$ & $M$ & $S D$ \\
\hline \multicolumn{7}{|c|}{ Response times (sec) } \\
\hline Related & 0.2 & 0.4 & 1.3 & 1.0 & 1.2 & 0.6 \\
\hline Unrelated & 1.2 & 1.0 & 1.7 & 1.3 & 1.9 & 0.7 \\
\hline \multicolumn{7}{|c|}{ Recognition memory (\% correct) } \\
\hline Related & 84.17 & 12.39 & 79.17 & 14.03 & 66.20 & 11.31 \\
\hline Unrelated & 87.92 & 8.66 & 84.58 & 8.57 & 61.57 & 11.56 \\
\hline
\end{tabular}

Note-AD, Alzheimer's disease.

iment 1 for a PM response to qualify as successful because of the extra time required to turn and locate the space bar of the computer keyboard. (No participant took longer than $6 \mathrm{sec}$ from target onset to make a response.) Response times were again recorded to the nearest second (see note 2 ).

PM performance. The mean numbers of $P M$ successes out of five in the related and unrelated conditions are shown in Figure 3 for young adults, older adults, and AD patients. Performance was at or close to ceiling for young adults. The young adults outperformed the older adults, who, in turn, outperformed the AD patients. The related and unrelated conditions resulted in similar performance in all three groups.

As in Experiment 1, the young group was excluded from a two-way factorial ANOVA on these data with group ( 2 levels: older and $\mathrm{AD}$ patients) and task (2 levels: related and unrelated) as factors. This revealed a significant effect of group $\left[F(1,34)=7.22, M S_{\mathrm{e}}=1.33, p<\right.$ .02]. Neither the effect of task nor the interaction between group and task reached significance (both $F_{\mathrm{S}}<1$ ).

The mean latencies for successful PM responses in each condition are shown in Table 4. It can be seen that the young adults were faster than the older adults and $\mathrm{AD}$ patients, and that responses in the related condition were faster than those in the unrelated condition. A two-way factorial ANOVA revealed significant effects of group $\left[F(2,52)=5.45, M S_{\mathrm{e}}=0.81, p<.01\right]$ and condition $\left[F(1,52)=9.11, M S_{\mathrm{e}}=0.81, p<.01\right]$, with no interaction between them $(F<1)$. Post hoc Newman-Keuls comparisons revealed that the young adults were significantly faster than both the older adults and the AD patients $(p s<.01)$, who did not differ.

Recognition memory performance. The mean percentages of correct responses on the recognition memory test completed after film viewing are shown in Table 4. These data were analyzed with group (3 levels) and PM task (2 levels: related and unrelated) as between-subjects factors. There was a significant effect of group $[F(2,52)=$ 20.44, $\left.M S_{\mathrm{e}}=126.56, p<.001\right]$, with Newman-Keuls comparisons revealing that the $\mathrm{AD}$ patients performed significantly less well than either the young adults or the older adults, who themselves did not differ significantly. There was no significant difference between the two tasks $(F<1)$ and no interaction between group and task $\left[F(2,52)=1.07, M S_{\mathrm{e}}=126.56, p>.10\right]$. 
Table 5

Correlations Between Age and Scores for Older Adults in the Event-Based Condition of Experiment 1 and Related and Unrelated (Event-Based) Conditions of Experiment 2

\begin{tabular}{ll}
\hline Measure & $r(33)$ \\
\hline PM successes & $-.45 * *$ \\
Recognition & $-.60 * *$ \\
Digit span & $-.39 *$ \\
Sentence span & $-.33 *$ \\
Free recall & $-.56 * *$ \\
\hline
\end{tabular}

${ }^{*} p \leq .05 . \quad{ }^{*} p<.01$.

\section{Discussion}

As in Experiment 1, there was good retention of the PM task instructions and yet there were PM deficits associated with both normal aging and dementia. Thus older adults made numerically fewer successful PM responses and were significantly slower in producing them than were young adults. AD patients were significantly less successful than older adults but not significantly slower.

In terms of the numbers of successful PM responses, there was no difference between the related and unrelated cue-action conditions for any of the groups. However, PM responses were significantly faster when the cue and action were related than when they were unrelated. Our expectation was that the effects of both aging and dementia would be reduced in the related (clock-clock) condition relative to the unrelated (animal-clock) condition because, in the former case, retrieval of the appropriate action (i.e., stop the clock) in response to the cue (clock) would be primed by the cue itself. This manipulation was apparently not strong enough to influence whether or not participants successfully responded; however, it was at least successful in producing faster response times in the related than in the unrelated condition. ${ }^{6}$ Contrary to prediction, there was no evidence of differential effects of condition on the PM response times across the three groups. However, with very few trials contributing to the mean response times for each participant, it is probably unrealistic to expect significant group $\times$ task interactions for this particular measure of performance. The results do at least suggest that even the performance of AD patients can be sensitive to subtle manipulations of the PM task.

\section{COMBINED ANALYSES}

\section{Effects of Normal Aging and Dementia on PM Versus RM}

In this section, we address the crucial issue raised in the introduction of the relative effects on PM and RM of both normal aging and dementia. For normal aging, the comparison between young and older adults in both experiments revealed modest PM deficits in the context of substantial decline in free recall, but no decline in digit span, sentence span, or recognition. Thus, we have evidence that performance on these particular laboratory-based PM tasks is neither unusually spared (see Einstein \& McDaniel, 1990) nor unusually impaired (see Craik, 1986) by normal aging. The very close similarity between the numbers of PM successes in the event-based condition of Experiment 1 and the related and unrelated event-based conditions of Experiment 2 (see Figures 1 and 3) is fortuitous because it allows us to combine the data across experiments to conduct more quantitative comparisons. Table 5 shows the correlations between age and performance for older adults only (since young adults were at or close to ceiling in the event-based tasks). ${ }^{7}$ It can be seen that for these participants, with an age range of 55 to 80 years, there were significant negative correlations with age for all measures. The strongest correlation was for recognition, which is surprising in view of the absence of significant differences between the young and older adults in both experiments. However, a scatterplot of age against recognition scores for the older adults in Table 5 revealed that those in their 50s and early 60 s performed above the young mean whereas the over-75s performed well below the young mean. Two factors may have contributed to this: (1) The older adults may have been more familiar with the Aberdeen area than the young adults, and (2) the recognition task may have been a particularly difficult one for the very old participants because the scene as depicted on the still photograph may have matched the film exactly for only a brief period of time. The recognition correlation was followed by free recall, PM, sentence span, and digit span. Note again that there is no strong evidence that PM is unusual in its sensitivity to the effects of normal aging.

For dementia, clearly the AD patients performed significantly worse than the age-matched older adults across all memory tasks. To compare the effects of AD on PM and RM directly, we pooled the data from the older adults and $\mathrm{AD}$ patients from the event-based condition of Experiment 1 and the related and unrelated event-based conditions of Experiment $2(n=65)$ and calculated standardized scores. The means are presented in Table 6 , together with the results of $t$ tests comparing the older adults and $\mathrm{AD}$ patients. ${ }^{8}$ The strongest effect of $\mathrm{AD}$ was for recognition, followed by free recall, sentence span, digit span, and finally PM. Again, the ordering of RM tasks did not exactly correspond to predictions, perhaps because of the use of an unusual recognition test with nonverbal materials. Nevertheless, there were striking parallels between the patterns for normal aging and demen-

\section{Table 6}

Standardized Scores for Older Adults and AD Patients in the Event-Based Condition of Experiment 1 and Related and Unrelated (Event-Based) Conditions of Experiment 2

\begin{tabular}{|c|c|c|c|c|c|}
\hline \multirow[b]{2}{*}{ Measure } & \multicolumn{2}{|c|}{$\begin{array}{c}\text { Older } \\
(n=35)\end{array}$} & \multicolumn{2}{|c|}{$\begin{array}{l}\text { AD Patients } \\
(n=30)\end{array}$} & \multirow{2}{*}{$\begin{array}{c}\text { Difference } \\
t(63)\end{array}$} \\
\hline & $M$ & $S D$ & $M$ & $S D$ & \\
\hline PM successes & 0.48 & 0.64 & -0.56 & 1.06 & $4.91^{*}$ \\
\hline Recognition & 0.64 & 0.77 & -0.74 & 0.67 & $7.62 *$ \\
\hline Digit span & 0.59 & 0.80 & -0.68 & 0.75 & $6.56^{*}$ \\
\hline Sentence span & 0.57 & 0.67 & -0.66 & 0.92 & $6.24 *$ \\
\hline Free recall & 0.63 & 0.77 & -0.74 & 0.69 & $7.52 *$ \\
\hline
\end{tabular}

Note-AD, Alzheimer's disease. $* p<.001$. 
Table 7

Correlations Between PM and RM Scores For the Older Adults in the Event-Based Conditions of Experiments 1 and 2 $(n=35)$ and Factor Analysis Loadings (Oblique Solution)

\begin{tabular}{lccccccc}
\hline & \multicolumn{3}{c}{ Correlations } & & \multicolumn{2}{c}{ Loadings } \\
\cline { 2 - 5 } \cline { 7 - 8 } & Recog & DS & SS & FR & & Factor 1 & Factor 2 \\
\hline PM successes & $.37^{*}$ & -.02 & .09 & .22 & & .00 & .97 \\
Recognition & - & $.53^{* *} .39^{*}$ & $.48^{* *}$ & & .66 & .48 \\
Digit span & & - & $.42^{*}$ & $.43^{*}$ & & .81 & -.11 \\
Sentence span & & & - & $.59^{* *}$ & & .79 & .02 \\
Free recall & & & & - & & .77 & .24 \\
\hline
\end{tabular}

Note-Recog, recognition; DS, digit span; SS, sentence span; FR, free recall. $* p<.05$. ** $p<.01$.

tia with respect to RM (see Tables 5 and 6). Contrary to Huppert and Beardsall's (1993) proposal, there was no evidence that PM was more impaired by AD than was RM.

A rather different (but nevertheless important) question is the extent to which PM deficits associated with normal aging and dementia can be predicted by RM deficits. This was addressed by again focusing on the event-based conditions from the two experiments. For normal aging, we conducted a multiple regression analysis on the older adults' data $(n=35)$ in which the predicted variable was the number of PM successes, and the predictor variables were the four measures of RM and age. (For correlations between PM and RM, see Table 7.) There were no significant independent contributions to the variance, but the effect of age approached significance $[t=-1.78, p=.08]$. With age included in the regression equation, $R^{2}$ increased from .218 to .296; age therefore accounted for an additional $7.8 \%$ of the variance over and above the measures of RM.

For an assessment of the effects of dementia, the data for older adults and $\mathrm{AD}$ patients $(n=65)$ were entered into a multiple regression analysis with PM successes as the predicted variable and the RM measures, age, and group $(0=$ older adults; $1=\mathrm{AD}$ patients) as predictor variables. ${ }^{9}$ Again, no variable made an independent contribution to the variance, although group approached significance $[t=$ $-1.96, p=.055]$. $R^{2}$ increased from .300 to .343 when group was added to the regression equation, $\mathrm{AD}$ thereby accounting for an independent $4.3 \%$ of the variance in PM when RM measures and age were taken into account.

\section{Factor Analysis}

The data from the 35 older adults in the event-based conditions of Experiments 1 and 2 were further analyzed by conducting a factor analysis on PM and RM scores. Table 7 shows both the correlation matrix and the loadings for the two factors produced by the oblique solution reference structure. It can be seen that there is clear evidence for separate (although correlated) factors of RM (factor 1) and PM (factor 2), and these accounted for $49.9 \%$ and $21.3 \%$ of the variance, respectively. The same pattern emerged from factor analyses of (1) older adults and $\mathrm{AD}$ patients in all event-based conditions $(n=65)$, and (2) older adults and AD patients in both event- and time-based conditions ( $n=92)$, except that in both these cases the separation between the two factors was even clearer, with recognition loadings resembling those of the other RM measures.

\section{CONCLUSIONS}

The present study is the first to demonstrate significant deficits in the PM component of laboratory-controlled PM tasks in patients suffering from AD in comparison with age-matched controls. Importantly, the AD patients' PM failures were not due to misunderstanding or forgetting the task instructions; instead, AD patients simply failed more often to carry out the PM task in response to the appropriate cue (as, indeed, did older adults in comparison with young adults; see also Maylor, 1998). The findings demonstrate that PM can be investigated experimentally in $\mathrm{AD}$, although in achieving above-floor performance from $\mathrm{AD}$ patients, there were ceiling effects for young adults on the same tasks.

Contrary to predictions, there was no evidence of differential effects of AD on time- versus event-based PM tasks (Experiment 1) or on unrelated versus related cue-action conditions (Experiment 2). In the case of Experiment 1 , the dementia findings mirror our normal aging data using the same tasks (Logie et al., 2001). We would therefore argue that time-based tasks may not necessarily be more demanding than event-based tasks in terms of the degree of self-initiated activity required or environmental support available. For example, in our event-based task, participants had to remember to scan the whole of each scene for the appearance of an animal, whereas in our time-based task, participants could "forget" about the PM task for a couple of minutes after making a successful response. Note also that it is very difficult to design time- and event-based tasks that differ only in terms of whether the cue for action is a particular time or event. In both Experiment 1 and previous studies (e.g., Einstein et al., 1995), the task instructions were slightly lengthier for the time-based task in order to explain the clockface, the location of the space bar, and so on. In summary, there are good reasons for supposing that we should not always expect a greater deficit in time- than in eventbased PM tasks as a result of either normal aging or dementia. Experiment 2 was an attempt to focus on a manipulation of retrieval demands within event-based tasks. This was clearly insufficient to influence PM success, although response times were more sensitive to the manipulation, even in AD patients. Like West and Craik (1999), we conclude that useful information may be obtained by examining not only whether or not participants respond to PM targets, but how quickly they respond.

The clock-checking behavior in the time-based PM task of Experiment 1 revealed that older adults and AD patients checked the clock more often than did young adults prior to making a successful PM response. Previous studies (e.g., Einstein et al., 1995; Park et al., 1997) have attributed age deficits in time-based PM tasks to reduced 
clock-checking (self-initiated) behavior, but they did not distinguish between PM successes and failures. The present breakdown of results is more consistent with the view that momentary lapses of intention are primarily responsible for time-based PM deficits in normal aging and dementia (as they are in event-based tasks; see Maylor, 1993a, 1996a; West \& Craik, 1999), although deficits in other factors such as time estimation (e.g., Craik \& Hay, 1999) and distractibility (e.g., Hasher \& Zacks, 1988; McDowd, Oseas-Kreger, \& Filion, 1995) may also play a role.

Importantly, the present data allowed us to compare the effects of both normal aging and dementia on PM and RM tasks. Note, first, that the rank ordering of the four RM tasks with respect to correlations with age for older adults (Table 5) was identical to that of the differences between the standardized scores of older adults and AD patients (Table 6). This provides further evidence of similarity between the effects of normal aging and dementia on RM. In contrast, on this analysis, PM was actually more impaired by normal aging than at least some of the RM tasks (namely, span tasks), whereas PM was less impaired by dementia than all four of the RM tasks. This result would seem to suggest that PM is not disproportionately impaired by dementia relative to RM (or, at least, that our particular PM tasks are not more impaired than any of our sample of RM tasks). This is consistent with our questionnaire data (Smith et al., 2000), in which carers reported that AD patients' PM failures were no more frequent (albeit more frustrating) than their RM failures in everyday life. Together, these findings would seem to argue against Huppert and Beardsall's (1993) proposal that PM tasks are particularly sensitive to the early stages of dementia. However, it should be acknowledged that the present $\mathrm{AD}$ patients were not necessarily in the early stages of dementia since they had been attending the Memory Clinic for an average of 31.5 months. Further empirical work (requiring a longitudinal design) is therefore necessary to determine whether PM failures are earlier indicators of dementia than are RM failures.

The regression analyses reveal some similarity between the effects of normal aging and dementia on PM such that there were trends in both cases to suggest that neither effect can be entirely accounted for by RM deficits. Previous studies have also revealed significant effects of age in multiple regression analyses on PM performance after measures of current cognitive ability (including fluid and crystallized intelligence and processing speed) have been taken into account (e.g., Cockburn \& Smith, 1991; Mäntylä $\&$ Nilsson, 1997; Maylor, 1998). Further work is required to determine what factors are responsible for the remaining age-related, and now dementia-related, variance. One possibility is that the relationship between normal aging and PM may be particularly associated with decline in frontal (dorso-lateral) functioning (on the frontal hypothesis of aging, see Moscovitch \& Winocur, 1992; Parkin, 1997; Perfect, 1997; Phillips \& Della Sala, 1999; West,
1996; on its relationship to PM, see Bisiacchi, 1996; Glisky, 1996; McDaniel, Glisky, Rubin, Guynn, \& Routhieaux, 1999). Certainly, patients with lesions of the frontal lobes have been found to be particularly impaired on PM tasks (Cockburn, 1995; Shallice \& Burgess, 1991). It remains to be determined whether the unique variance associated with normal aging and dementia can be attributable to frontal decline.

Finally, although the present study did not show differential effects of either normal aging or dementia on PM and RM, the results from factor analysis of the older adults' data revealed separate PM and RM factors. Thus, the present findings from objective measures of memory converge with data from a self-rated questionnaire of everyday PM and RM failures, which revealed distinct PM and RM factors in its latent structure (Crawford, Smith, Maylor, Della Sala, \& Logie, in press). Together, these results are at least consistent with arguments that $\mathrm{PM}$ and RM tasks may depend on different processes and/or different brain areas, with PM tasks more reliant on executive processes such as strategic planning, self-initiated retrieval, and task interruption or switching (see Brandimonte et al., 1996; McDaniel et al., 1999, for discussion).

\section{REFERENCES}

Baddeley, A., Logie, R., Bressi, S., Della Sala, S., \& Spinnler, H. (1986). Senile dementia and working memory. Quarterly Journal of Experimental Psychology, 38A, 603-618.

BISIACCHI, P. S. (1996). The neuropsychological approach in the study of prospective memory. In M. Brandimonte, G. O. Einstein, \& M. A. McDaniel (Eds.), Prospective memory: Theory and applications (pp. 297-317). Mahwah, NJ: Erlbaum.

Brandimonte, M., Einstein, G. O., \& McDaniel, M. A. (Eds.) (1996). Prospective memory: Theory and applications. Mahwah, NJ: Erlbaum.

Camp, C. J., Foss, J. W., Stevens, A. B., \& O'Hanlon, A. M. (1996). Improving prospective memory task performance in persons with Alzheimer's disease. In M. Brandimonte, G. O. Einstein, \& M. A. McDaniel (Eds.), Prospective memory: Theory and applications (pp. 351367). Mahwah, NJ: Erlbaum.

Capitani, E., Della Sala, S., Logie, R. H., \& Spinnler, H. (1992). Recency, primacy, and memory: Reappraising and standardising the serial position curve. Cortex, 28, 315-342.

Ceci, S. J., Baker, J. G., \& Bronfenbrenner, U. (1988). Prospective remembering, temporal calibration, and context. In M. M. Gruneberg, P. E. Morris, \& R. N. Sykes (Eds.), Practical aspects of memory: Current research and issues. Vol. 1: Memory in everyday life (pp. 360365). Chichester, U.K.: Wiley.

Ceci, S. J., \& Bronfenbrenner,U. (1985). "Don't forget to take the cupcakes out of the oven": Prospective memory, strategic time-monitoring, and context. Child Development, 56, 152-164.

CockbURn, J. (1995). Task interruption in prospective memory: A frontal lobe function? Cortex, 31, 87-97.

Cockburn, J., \& Sмith, P. T. (1988). Effects of age and intelligence on everyday memory tasks. In M. M. Gruneberg,P. E. Morris, \& R. N. Sykes (Eds.), Practical aspects of memory: Current research and issues. Vol. 2: Clinical and educational implications (pp. 132-136). Chichester, U.K.: Wiley.

Cockburn, J., \& Smith, P. T. (1991). The relative influence of intelligence and age on everyday memory. Journal of Gerontology: Psychological Sciences, 46, P31-36.

CraIK, F. I. M. (1986). A functional account of age differences in memory. In F. Klix \& H. Hagendorf (Eds.), Human memory and cognitive 
capabilities: Mechanisms and performances (pp. 409-422). Amsterdam: Elsevier.

Craik, F. I. M., Anderson, N. D., Kerr, S. A., \& Li, K. Z. H. (1995). Memory changes in normal aging. In A. D. Baddeley, B. A. Wilson, \& F. N. Watts (Eds.), Handbook of memory disorders (pp. 211-241) Chichester, U.K.: Wiley.

CraIK, F. I. M., \& HAY, J. F. (1999). Aging and judgments of duration: Effects of task complexity and method of estimation. Perception \& Psychophysics, 61, 549-560.

Craik, F. I. M., \& Kerr, S. A. (1996). Commentary: Prospective memory, aging, and lapses of intention. In M. Brandimonte, G. O. Einstein, \& M. A. McDaniel (Eds.), Prospective memory: Theory and applications (pp. 173-197). Hillsdale, NJ: Erlbaum.

Crawford, J. R., Smith, G., Maylor, E. A., Della Sala, S., \& LogIe, R. H. (in press). The Prospective and Retrospective Memory Questionnaire (PRMQ): Normative data and latent structure in a large non-clinical sample. Memory.

Duff, S. C., \& LogIE, R. H. (2001). Processing and storage in working memory span. Quarterly Journal of Experimental Psychology, 54A, 31-48.

D'Ydewalle, G., Luwel, K., \& BRunfaut, E. (1999). The importance of ongoing concurrent activities as a function of age in time- and event-based prospective memory. European Journal of Cognitive Psychology, 11, 219-237.

Einstein, G. O., Holland, L. J., McDaniel, M. A., \& Guynn, M. J. (1992). Age-related deficits in prospective memory: The influence of task complexity. Psychology \& Aging, 7, 471-478.

Einstein, G. O., \& McDaniel, M. A. (1990). Normal aging and prospective memory. Journal of Experimental Psychology: Learning, Memory, \& Cognition, 16, 717-726.

Einstein, G. O., McDaniel, M. A., Manzi, M., Cochran, B., \& BAKER, M. (2000). Prospective memory and aging: Forgetting intentions over short delays. Psychology \& Aging, 15, 671-683.

Einstein, G. O., McDaniel, M. A., Richardson, S. L., Guynn, M. J., \& Cunfer, A. R. (1995). Aging and prospective memory: Examining the influences of self-initiated retrieval processes. Journal of Experimental Psychology: Learning, Memory, \& Cognition, 21, 996-1007.

Einstein, G. O., Smith, R. E., McDaniel, M. A., \& Shaw, P. (1997). Aging and prospective memory: The influence of increased task demands at encoding and retrieval. Psychology \& Aging, 12, 479-488

Folstein, M. F., Folstein, S. E., \& McHugh, P. R. (1975). MiniMental State: A practical method for grading the cognitive state of patients for the clinician. Journal of Psychiatric Research, 12, 189-198.

GLISKY, E. L. (1996). Prospective memory and the frontal lobes. In M. Brandimonte, G. O. Einstein, \& M. A. McDaniel (Eds.), Prospective memory: Theory and applications (pp. 249-266). Mahwah, NJ: Erlbaum.

Harris, J. E., \& WiLKINS, A. J. (1982). Remembering to do things: A theoretical framework and an illustrative experiment. Human Learning, 1, 123-136.

HASHER, L., \& ZACKS, R. T. (1988). Working memory, comprehension, and aging: A review and a new view. In G. H. Bower (Ed.), The psychology of learning and motivation (Vol. 22, pp. 193-225). New York: Academic Press.

Hohaus, L., Shum, D., White, J., \& CAIRd, D. (2000, April). The effect of salience on prospective memory declines with age. Paper presented at the Eighth Cognitive Aging Conference, Atlanta.

Hultsch, D. F., Hertzog, C., Dixon, R. A., \& Small, B. J. (1998). Memory change in the aged. Cambridge: Cambridge University Press.

Huppert, F. A., \& BeArdsall, L. (1993). Prospective memory impairment as an early indicator of dementia. Journal of Clinical and Experimental Neuropsychology, 15, 805-821.

HupPert, F. A., Johnson, T., \& Nickson, J. (2000). High prevalence of prospective memory impairment in the elderly and in early-stage dementia: Findings from a population-based study. Applied Cognitive Psychology, 14, S63-S81

Kidder, D. P., Park, D. C., Hertzog, C., \& Morrell, R. (1997). Prospective memory and aging: The effects of working memory and prospective memory task load. Aging, Neuropsychology, \& Cognition, 4, 93-112.

Kvavilashvili,L. (1992). Remembering intentions: A critical review of existing experimental paradigms. Applied Cognitive Psychology, $\mathbf{6}$, 507-524.

Logie, R. H., Maylor, E. A., Della Sala, S., \& Smith, G. (2001). Effects of working memory demands on age differences in prospective memory. Manuscript submitted for publication.

MäNTY LÄ, T., \& NILSSON, L.-G. (1997). Remembering to remember in adulthood: A population-based study of aging and prospective memory. Aging, Neuropsychology, \& Cognition, 4, 81-92.

MAYLOR, E. A. (1990). Age and prospective memory. Quarterly Journal of Experimental Psychology, 42A, 471-493.

MAYLOR, E. A. (1993a). Aging and forgetting in prospective and retrospective memory tasks. Psychology \& Aging, 3, 420-428.

MAYLOR, E. A. (1993b). Minimized prospective memory loss in old age. In J. Cerella, J. Rybash, W. Hoyer, \& M. L. Commons (Eds.), Adult information processing: Limits on loss (pp. 529-551). San Diego: Academic.

MaYlor, E. A. (1995). Prospective memory in normal aging and dementia. Neurocase, 1, 285-289.

MaYlor, E. A. (1996a). Age-related impairment in an event-based prospective memory task. Psychology \& Aging, 11, 74-78.

MAY LOR, E. A. (1996b). Does prospective memory decline with age? In M. Brandimonte, G. O. Einstein, \& M. A. McDaniel (Eds.), Prospective memory: Theory and applications (pp. 173-197). Mahwah, NJ: Erlbaum.

MAYLOR, E. A. (1998). Changes in event-based prospective memory across adulthood. Aging, Neuropsychology, \& Cognition, 5, 107-128.

May lor, E. A., Darby, R. J., Logie, R. H., Della Sala, S., \& Smith, G. (2002). Prospective memory across the lifespan. In P. Graf \& N. Ohta (Eds.), Lifespan development of human memory (pp. 235-256). Cambridge, MA: MIT Press.

McDaniel, M. A., Glisky, E. L., Rubin, S. R., Guynn, M. J., \& Routhieaux, B. C. (1999). Prospective memory: A neuropsychological study. Neuropsychology, 13, 103-110.

McDowd, J. M., Oseas-Kreger,D. M., \& Filion, D. L. (1995). Inhibitory processes in cognition and aging. In F. N. Dempster \& C. J. Brainerd (Eds.), Interference and inhibition in cognition (pp. 363-400). San Diego: Academic Press.

McKhann, G., Drachmann, P., Folstein, M., Katzman, R., Price, P., \& STADLER, E. (1984). Clinical diagnosis of Alzheimer's disease: Report of the NINCDS-ADRDA work group under the auspices of the Department of Health and Human Services task force on Alzheimer's disease. Neurology, 34, 939-944.

McKitrick, L. A., Camp, C. J., \& Black, F. W. (1992). Prospective memory intervention in Alzheimer's disease. Journal of Gerontology: Psychological Sciences, 47, 337-343.

MoRris, R. G. (1996). The cognitive neuropsychology of Alzheimer-type dementia. Oxford: Oxford University Press.

Moscovitch, M., \& Winocur, G. (1992). The neuropsychology of memory and aging. In F. I. M. Craik \& T. A. Salthouse (Eds.), The handbook of aging and cognition (pp. 315-372). Hillsdale, NJ: Erlbaum.

Nebes, R. D. (1992). Cognitive dysfunction in Alzheimer's disease. In F. I. M. Craik \& T. A. Salthouse (Eds.), The handbook of aging and cognition (pp. 373-445). Hillsdale, NJ: Erlbaum.

Park, D. C., Hertzog, C., Kidder, D. P., Morrell, R. W., \& MaYHORN, C. B. (1997). Effect of age on event-based and time-based prospective memory. Psychology \& Aging, 12, 314-327.

PARKIN, A. J. (1997). Normal age-related memory loss and its relation to frontal lobe dysfunction. In P. Rabbitt (Ed.), Methodologyof frontal and executive function (pp. 177-190). Hove, U.K.: Psychology Press.

Perfect, T. (1997). Memory aging as frontal lobe dysfunction. In M. A. Conway (Ed.), Cognitive models of memory (pp. 315-339). Hove, U.K.: Psychology Press.

Phillips, L. H., \& Della Sala, S. (1999). Aging, intelligence, and anatomical segregation in the frontal lobes. Learning \& Individual Differences, 10, 217-243.

Prull, M. W., Gabrieli, J. D. E., \& Bunge, S. A. (2000). Age-related changes in memory: A cognitive neuroscience perspective. In F. I. M. Craik \& T. A. Salthouse (Eds.), The handbook of aging and cognition (2nd ed., pp. 91-153). Mahwah, NJ: Erlbaum.

RAввIтT, P. (1996). Why are studies of "prospective memory" planless? In M. Brandimonte, G. O. Einstein, \& M. A. McDaniel (Eds.), Prospec- 
tive memory: Theory and applications (pp. 239-248). Hillsdale, NJ: Erlbaum.

Salthouse, T. A. (1991). Theoretical perspectives on cognitive aging. Hillsdale, NJ: Erlbaum.

Shallice, T., \& Burgess, P. W. (1991). Deficits in strategy application following frontal lobe damage in man. Brain, 114, 727-741.

Sinnott, J. D. (1989). Prospective/intentional memory and aging: Memory as adaptive action. In L. W. Poon, D. C. Rubin, \& B. A. Wilson (Eds.), Everyday cognition in adulthood and late life (pp. 352369). Cambridge: Cambridge University Press.

Smith, G., Della Sala, S., Logie, R. H., \& Maylor, E. A. (2000). Prospective and retrospective memory in normal aging and dementia: A questionnaire study. Memory, 8, 311-321.

SPINNLER, H. (1999). Alzheimer's disease: Neuropsychological defects according to the topographical spreading of neuronal degeneration. In F. Denes \& L. Pizzamiglio (Eds.), Handbook of clinical and experimental neuropsychology (pp. 699-746). Hove, U.K.: Psychology Press.

Spinnler, H., \& Della Sala, S. (1988). The role of clinical neuropsychology in the neurological diagnosis of Alzheimer's disease. Journal of Neurology, 235, 258-272.

WEST, R. L. (1996). An application of prefrontal cortex function theory to cognitive aging. Psychological Bulletin, 120, 272-292.

West, R. [L.], \& CraiK, F. I. M. (1999). Age-related decline in prospective memory: The roles of cue accessibility and cue sensitivity. Psychology \& Aging, 14, 264-272.

Wilcock, J. K., Hope, R. A., Oppenheimer, C., Reynolds, J. P., Rossor, M. N., \& DAvies, M. B. (1989). Recommended minimum data to be collected in research studies on Alzheimer's Disease. Journal of Neurology, Neurosurgery, \& Psychiatry, 52, 693-700.

Wilson, B. A., Cockburn, J., \& BAdDeley, A. D. (1985). The Rivermead behavioural memory test. Titchfield, U.K.: Thames Valley Test Co.

Zacks, R. T., HASHER, L., \& Li, K. Z. H. (2000). Human memory. In F. I. M. Craik \& T. A. Salthouse (Eds.), The handbook of aging and cognition (2nd ed., pp. 293-357). Mahwah, NJ: Erlbaum.

\section{NOTES}

1. The film length of 17 min ensured that if participants were late in responding after $3 \mathrm{~min}$ had elapsed, there were always five opportunities for PM responses.

2. Throughout, responses between 0 and $0.5 \mathrm{sec}$ were entered as $0 \mathrm{sec}$, between 0.5 and $1.5 \mathrm{sec}$ as $1.0 \mathrm{sec}$, and so on. Hence, mean response times of $0 \mathrm{sec}$ were possible.
3. It may seem unduly strict to expect participants (especially older people) to produce a response within $2 \mathrm{sec}$ after the target time. But note that participants had the opportunity to watch the clock up to the target time and therefore achieve accurate responses by anticipating the clock reaching $3 \mathrm{~min}$. Results using more lenient time windows for correct responses are presented later.

4. Extending the time window for successful responses in the timebased task to between $2 \mathrm{sec}$ before and $4 \mathrm{sec}$ after the target time resulted in means of 3.60 and 2.67 for the older group and AD patients, respectively. Note that, on this criterion, the difference between the two older groups was actually smaller for the time-based task than for the eventbased task.

5. This latter suggestion may seem inconsistent with the finding that performance on the ongoing task (as measured by recognition memory) did not differ between young and older participants. However, it is very unlikely that the older group's additional clock checks coincided with any of the 12 scenes from the 17-min film used in the recognition test.

6. One possible explanation for this result is that the particular clocks in the film may have been easier to detect than the animals. To test this possibility, a simple vigilance task was conducted with a group of young adults $(n=12$; mean age $=21$ years) recruited from the same sources as those in Experiments 1 and 2. Participants were asked to view both the clock and the animal films (with order counterbalanced) and to press the space bar of the computer as quickly as possible whenever a target (clocks or animals, depending on the film) appeared. Participants responded to all the clocks and animals within $6 \mathrm{sec}$ of their appearance, with the exception of 1 participant who missed an animal. The mean response times were $1.6 \mathrm{sec}(S D=0.7)$ for clocks and $1.5 \mathrm{sec}(S D=0.6)$ for animals, with no significant difference between them $[t(11)<1]$, thereby discounting the possibility that clocks were easier to detect than animals.

7. The correlations between age and RM scores were similar to those shown in Table 5 when the older adults assigned to the time-based condition of Experiment 1 were also included.

8 . The standardized scores for PM successes in the time-based condition of Experiment 1 were as follows: $M=0.38, S D=0.95$ for older adults; $M=-0.47, S D=0.88$ for AD patients $[t(25)=2.37, p<.05]$.

9. There were significant correlations between PM and each of the RM measures $(n=65)$ : .46 (recognition), . 39 (digit span), . 45 (sentence span), and .50 (free recall).

(Manuscript received August 18, 2000; revision accepted for publication April 26, 2002.) 